\title{
"Digital Health Earth": towards a global healthcare management geolocating human health condition by means of space technology
}

\author{
Antonio Del Mastro $^{* 1} \mid$ Federico Monaco $^{2} \mid$ Eugene Eremchenko $^{3} \mid$ Anna Nelson $^{4}$ \\ ${ }^{1}$ Mars Planet Research\&Innovation, Curno, Italy, info@marsplanet.org \\ ${ }^{2}$ University of Parma, Parma, Italy, monaco.federico@gmail.com \\ ${ }^{3}$ Lomonosov Moscow State University, Moscow, Russia, eugene.eremchenko@gmail.com \\ ${ }^{4}$ Independent Researcher, Kuala Lumpur, Malaysia, info@marsplanet.org
}

\begin{abstract}
Healthcare providers such as the World Health Organization, transnational and global health initiatives, the national healthcare systems, down to the smallest villages and individual practitioners and professionals could benefit from geo referential data and metadata and 3D digital assets provided by space technology. Health prevention and literacy programs, mortality and morbidity rates, including contextual statistical data about populations and territories are being already produced and accessible. The hypothetical frame of a Digital Health Earth hereto presented could be performed as the interoperability of $3 \mathrm{D}$ representations of sectors of territories and geolocalized layers about health and environment. SDG Goals crossed with WHO programs and available data can become the premises for the design and development of a global representation of healthcare situations, highlighting priorities and disseminating data by intuitive and interactive modes of visualization as it is already happening with 2D dashboards about COVID-19 pandemic. Healthcare practitioners, professionals, health managers, but also patients, proxy, social workers, laypeople, stakeholders and media could benefit from visualizing and comparing Digital Earth health data. Concerns about privacy, digital divide and social exclusion from primary care services and how quality of lives might occur are considered here. As a consequence of Space Technology, especially for its connection with the Satellite industry, Digital Health Earth, will contribute to the development of a new added value economic branch inside the increasing market of the Space Economy Revolution.
\end{abstract}

Keywords

Digital Earth, health, neogeography.

\section{Introduction}

Since the Corpus Hippocraticus from the 5th Century B.C. empirical evidence has related medicine and healthcare to places. Peculiar situations and local conditions have always helped in healing and taking care of people, involving either practitioners, or laypeople. In fact, according to World Health Organization (WHO), health can be defined as "a state of complete physical, mental and social well-being and not merely the absence of disease or infirmity" (WHO.int, 1948). Nowadays and as evolution of the paper cartography, GIS can support quality of life given its usefulness in connecting data about phenomena, happening on local spots and at global level.

Science of medicine, surgery and healthcare have developed statistical means and records in order to understand phenomena and develop patterns, starting at local level by local resources. Globalization and networks could combine individual efforts and experiences into a global digital frame to provide information about health data, resources and actions.

\footnotetext{
Corresponding author
} 
Neogeography as an implementation of a new scientific principle and a summa of technological achievements (Turner, 2006) applied to healthcare could bring a new and integrated way to deliver health information literacy, produce research, provide care and enact prevention all over the globe. This might be possible starting from implementing world programs in health for Earth frame. In June 1992, at the Earth Summit in Rio de Janeiro, Brazil, more than 178 countries adopted the Agenda 21, a comprehensive plan of action to build a global partnership for sustainable development to improve human lives and protect the environment by 17 Sustainable Development Goals. Most of such goals feature a clear connection between health and environment, but still today is hard to harvest data about SDG and their impacts, probably as the quantity of data to be crunched are not providing yet the useful leverage to ad hoc policies to face the environmental disruption and the consequences on human life and condition.

Digital technologies can provide solutions to pursue such goals. Changes in the last decades must be monitored by ad hoc technologies (Shupeng \& van Genderen, 2008), especially on the quality of life and conditions about the habitat coming from the interaction with humans and between humans. It is be known how much the interaction of users with digital applications can be represented and tracked by data (Butler, 2006).

According to the International Society for Digital Earth (ISDE), Digital Earth is the result of “digital technologies to model Earth systems, including cultural and social aspects represented by human societies living on the planet" (ISDE, 2012). The concept of Digital Earth traces back to 1998 when Al Gore presented his visionary concept of a Digital Earth as a "a multi-resolution, three-dimensional representation of the planet, into which we can embed vast quantities of georeferenced data" (Gore, 1998). Talking about geospatial data, Gore outlined the difficulties of taking advantage of this vast amount of data. He envisioned applications where "information can be seamlessly fused with the digital map or terrain data" allowing the user to move through space and time. To achieve this vision, a collaborative effort from government, industry, academia and citizens is needed.

The Digital Earth might be defined as a global strategy (Chen, 1999) highly related to Geoinformation Science (Chen, 2004). A decade after the Gore's vision presentation, a Digital Earth project was presented. Since then, a global effort started developing a technology framework to preserve the planet in support of human societies (Liu, et al., 2020).

Therefore, the project of Digital Earth (Goodchild, 1999) might benefit as well from adding a health perspective to the project. 


\section{Health data driven dashboards towards 3D representation}

Digital technologies are already producing data about access, productivity, networks, reputational rates, areas, or other phenomena about users and their offline or online activities on websites, social network sites, or platforms; such layouts of multiple representations are called dashboards. Dashboard could be defined as a "visual display of the most important information needed to achieve one or more objectives; consolidated and arranged on a single screen so the information can be monitored at a glance" (Few, 2006). In our case, a possible definition for an online health dashboard is a two-dimension interface that provides visualization and interaction with data about health in a given area of the world, in a specific time span. During these last months, the design and adoption of dashboards have increased a lot, as they can monitor and represent pandemic situations and statistics about rates of infection, casualties and healed cases from the virus.

It can be stated that, due to the pandemic itself, the connection of information age and real time health issues have been cleared and made computationally working (Geraghty \& Frye, 2020). A vivid example comes from a former project of John Hopkins University developing a dashboard able to crunch data and provide real time data queries about the covid pandemic.

Further examples of health dashboards created to monitor COVID-19 can be considered Italian dashboard (FBK.eu, 2020), thanks to a partnership with WHO (Tangcharoensathien, et al., 2020), including visualizations about collective sentiment and psychology, social bot pollution and news reliability, and the one built by ESRI for the WHO directly (WHO.int, 2020a). The case of the WHO is very interesting as it entails three different web resources providing infodemics: a dashboard, the website and a news map.

Such dashboards provide global data about COVID-19 thanks 2D mapping of data about phenomena.

\section{Health analysis of the transport systems in pandemic age}

Based on a report made by ICAO, it demonstrates that air transportation is hugely impacted and has a direct effect on the transmission chain of the novel Coronavirus COVID-19 (ICAO.int, 2020). Most countries in the world imposed a lockdown measure to curb the problem where most of the international borders were closed between March till June. This measure had cost thousands 
and even millions of dollars of business loss. Following the ease of the lockdown to promote business activities, most countries started to implement new guidelines on travel practice to avoid or at least minimize the risk of COVID-19 resurgence. Therefore, the handling processes at the airport will be significantly changed as a consequence of the pandemic (Schultz, Sulaki, 2020), whereas aircraft seating arrangement will change in order to maintain the social distancing and minimize possible contacts amongst passengers and this will result in a slower transportation process at the airport. Thus an analytical approach to solve the problem of seating arrangement and passengers' movement in the aircraft during boarding was provided. Before the emergence of COVID-19 pandemic, the airlines industry has been studying on the most effective, cost saving aircraft boarding for passengers giving consideration on passengers' expectations as well as luggage and cabin bags handling which can be time consuming if not done systematically. Thus, it is reckoned that the new normal practice will drive the aviation industry to evaluate further the handling of passengers and airport management to meet the criteria of social distancing in order to minimize infection transmission.

Prior to data that could be obtained from aviation industry through airport management assessment, public health practitioners and epidemiologists can benefit the data of movements of passengers, cabin bags and luggage handlings at the airport and on board of aircraft, to evaluate the risk of transmission and predict the likelihood of infection spread globally. However, the movement of people travelling all over the world is fluid, thus a real-time data will be helpful. Therefore, a real-time Digital Health Earth that shows the movement of travelers at airports can be beneficial for public health practitioners and epidemiologists to predict the transmission rate and its propensity. Besides that, the real-time data can also be used by the governmental bodies as part of their considerations in developing international border policy which may change from time to time, due to the ongoing dynamic circumstances. In addition, general practitioners and travel medicine doctors can largely benefit this information as well in providing advice to their patients (provided that the data is accompanied with public health advice). It is not impossible that in the future, the study of people's movement that contributes to infection transmission based on Digital Health Earth will be part of adjunct syllabus in epidemiology or public health study.

The data will comprise of patterns of movement at the airport on boarding and landing, the routes of flights and the origins of flights. If such detailed information could be gathered and systematically grouped, public health practitioners and epidemiologists may be able to evaluate the import and export of disease transmission. In any disease outbreak, information is power. 
Nonetheless the data collected in Digital Health Earth must be regularly updated to get as accurate as possible to deepen our understanding of transmission patterns, severity, clinical features and risk factors for infection which were unknown at the beginning of the COVID-19 outbreak.

\section{Interoperability, sustainability and visions for a Digital Health Earth: a global approach}

WHO's actions could be represented as visible layers on a map if considered according to resources as the description of local and global phenomena about specific issues. Such resources are those available as WHO programmes, which could easily be eligible as layers: Alcohol and health, Child health, Cholera, Environmental health, Health systems financing, HIV/AIDS, Immunization, Malaria, Maternal and reproductive health, Mental health, Neglected tropical diseases, Noncommunicable diseases, Resources for the prevention and treatment of substance use disorders, Road safety, Tuberculosis, Urban health, Tobacco control, Violence prevention, Violence against women, Water and sanitation.

There are further issues that define public health issues as a connection between globalization and health (Labonte, Laverack, 2008), like global threat, priority settings, and health promotion (Lee, 2003). Especially in the field of Health Promotion, the World Health Statistics 2020 (WHO.int, 2020b) summarizes recent trends in life expectancy and reports on progress towards the main health and health-related Sustainable Development Goals (SDGs) and associated targets. It also assesses the current availability of those data, and describes how WHO is supporting countries to improve health information systems and global health security. The 2020 edition also includes four indicators (relating to poliomyelitis, hypertension and obesity in adults and school age children) from the Thirteenth General Programme of Work 2019-2023 (WHO.int, 2020c).

Digital Earth is envisaged as "a common platform to support national and international cooperation for global sustainable development, and a newly developing point of economic growth and social well-being" (ISDE, 2014).

The concept of a Digital Health Earth is here sketched and categorized according to present different possible needs and existing resources, means and goals and could be assessed within the context of Digital Earth concept, developed since 2006 under the umbrella of International Society for Digital Earth (ISDE) as a "non-governmental and not-for-profit international organization for promoting international collaboration towards the achievement of Digital Earth through academic 
exchange, science and technology innovation, education, and international collaboration" (ISDE, 2014).

Digital Earth is an integral initiative, intended to provide situational awareness as an ultimate interdisciplinary collector of data: "relying on collaborative efforts between Earth sciences, geospatial information and space sciences, Digital Earth aims to monitor and forecast natural and human phenomena on our planet" (Giuliani, Wang, 2019). Life data is vital for this purposes, therefore among the natural and human phenomena health and environmental conditions for human life should be considered. In order to save lives, take care of patients and run prevention programs, but also to increase the quality of life and monitor human health conditions and environmental situations in normal and emergency times a global interoperable and accessible solution is needed.

Human health be a global issue that must be tackled at global level; national (Boulos, 2004) and continental solutions (Gaughan, et al., 2014) for the Digital Earth project (Annoni, et al., 2011) are already out there. Spatial Explicity of data (Balk, et al. 2006) and global health needs and programs need now, more than ever, a transnational and transcontinental approach, and in the end a global approach.

COVID-19 Pandemic has shown us that restrictions to daily life to decrease risks mine the quality life at large. Computer supported activities and contexts out of activities of daily life can be data driven, i.e. quantified, monitored, crunched by emerging techniques such as dashboarding real life information, social network analysis in applications (SNAA), databasing, decision making and information.

Is time to adopt a global approach about health issues to simplify and make visual how research and experimentation in medicine and care include "uncertainty and probability" (Goodchild, et al., 2012). Information and Communication technologies can as well include the engagement of the public in such proposal by crowdsourcing mapping (Heipke, 2010) and data sharing.

Such hypothetical frame for a Digital Earth for health (Craglia, et al., 2012) should fill the lack of healthcare frame included as global issue in Al Gore's vision from the 90's.

Conditions come from the interoperability on georeference public health issues statistics (Cromley \& McLafferty, 2012), the technique of Geocoding Health Data (Rushton, et al., 2008), with the perspective of the WHO actions according to 17 SDG and other possible goals.

On the side of observing in real time phenomena about collective behaviour of populations, Earth observation (Anderson et al., 2017) and applications are already available, such as the 
Gridded Population of the World (GPW) collection that models the distribution of human population (counts and densities) on a continuous global raster surface (CIESIN, 2016).

Geographical application to monitor infections should be available as well on large scale (Linard \& Tatem, 2012), but also on global scale. Moreover, seamless integration of heterogeneous datasets generalized in the different scales is vital, therefore implementation of scale-less visualization principle become mandatory.

A visual 3D approach would make possible granting information and research according to big areas as well as small places, and even according to multi temporal (Freire, 2016) and global grids (Goodchild, 2000) for the study of population at global level (Pesaresi, et al., 2015; 2016) to access data about health conditions comparable to other data provided according to different geographical regions or historical times. The three-dimensional representation of high-rise urban development is extremely important for studying the spread of infections using man-made mechanisms, such as legionnaire's disease (Jomehzadeh et al, 2019). Of particular importance here is the creation of a highly accurate photo-visual model of the urban environment (Jackson, Simpson, 2020; Baturin et al, 2020) that allows for the precise localization of health and contextual information.

For instance, interdisciplinary approaches of population data (Deichmann, 2001) and census data (Doxsey-Whitfield, 2016) have become some requirements for Global Human Settlement Layer (GHSL) including parameters from the SDG in terms of socioeconomic data (Corbane, et al., 2017), the urban spatial print at global level (Melchiorri et al., 2018), and volunteer commitment (Goodchild, 2007) to contribute to map crisis events (de Longueville, 2010) and the availability of complex and interactive mapping. On the side of mapping there is already evidence of development on accuracy in mapping about population for public health uses (Hay, et al., 2005) in terms of validation on multi-temporal layers for land data for the benefit of the public involvement (Leyk, et al. 2018).

What is needed now is the involvement of institutions and research, the interoperability of scattered technologies and solutions around the globe adopted at local levels, a global health policy for Big and Open Data.

Nowadays, data intensive research is possible (Hey, 2009) and should find support around the world scientific medical community. A digital Health Earth project could solve Big Data problems (Guo et al., 2014). In terms of Big Earth Data there is the need to enwide applications and fields of human activities, such as healthcare although not yet envisioned (Guo et al, 2017). 
In a innovative Digital Earth perspective (Goodchild, et al., 2012) solutions and means must stay inclusive to people, and in this case also to patients. Digital Earth project itself should be the result of multiple uses (Goodchild, 2008). Mapping health situations could be pushed on a 3D level thanks also to a data global policy about Big \& Open Data (B\&OD).

The model for a digital twin of Earth related to health should, therefore, be a multidimensional, multiscale, multitemporal, and multilayered information system able to provide consistent visual data about health around the globe in all scales simultaneously.

WHO might be eligible as a favourable provider or endorser for a Digital Health Earth, given its global advocacy and historical/institutional role as international organization for health prevention and action for care in the whole world.

\section{Geolocalization and health related ethical questions}

Ethical requirements for Digital Earth (Georgiadou et al, 2020) and especially an ethical tension between the value of GIS in solving health-related issues and privacy concerns cannot be denied; health data and applications remain limited. However, there is an ongoing debate about licensing health data and explicit how big data (Ienca, et al., 2018) could become a benefit for public health in the coming future, given the strong practical example during the pandemic.

Application of GIS in public health and social services programs would make the difference in tackling emergencies and actions. Other applications would be of support to hospitals, but also insurance companies to detail and update statistics in order to profile and evaluate risks.

Global care and healthcare outcomes could be improved in the following ways: Determine access to care, connecting people with local resources, determine variation in health care services and outcomes, identify vulnerable populations - useful in emergency situations or in the regular course of public health work., understand clusters of disease and its causes, collect mobile data, providing new insight for better understanding of homeless populations and directing resources, where needed, More timely and efficient allocation of resources, Improving our response to disasters and disease, Strengthening collaboration between agencies and healthcare.

What is sure is that GIS data interoperability with healthcare systems, facilities and professionals is to breakthrough what traditional healthcare solutions can't detect (CDC.gov, 2012). 


\section{Geolocalization and health related ethical questions}

Main goals for a digital Health Earth would be to provide information about the main Who dimensions of intervention on world population:

- Morbidity, its Causes, and what actions;

- Mortality, its Causes, and what actions.

Sustainable Development Goals (SDG) such as the Goal\#3 "healthcare and ...quality of life" should address the development of a Digital Health Earth project intraoperative and integrated with the other neo geographical assets and Global issues networks in a global health perspective. Open data policies for health data should be fostered and education and training on Digital Earth applications for healthcare should be provided. Real-time data could be provided in case of risk situations, or natural disasters. Digital Health Earth could be used for education and to inspire future physicians and nurses and foster cooperation among hospitals, communities and institutions to increase safety and prevention practices.

While the entire world understands the benefits of using visualization for better health outcomes, countries which are showing immense progress in this realm are New Zealand, some states in US and Scandinavian countries. A flagship undertaking in this area is a new partnership focused on geo-health between the University of Canberra and the Dasman Diabetes Institute (DDI). The aim of the initiative is to tackle a serious public health concern - the disturbing prevalence of type 2 diabetes in Kuwait. Dr. Coffee and his team are building a geo-health data lab in Kuwait, which will help them in studying the variability in the disease's prevalence in the country, and thereby identify and analyze how location contributes to the situation (Geospatialworld.net, 2018).

The adoption of available GIS systems can provide global tools for the application of digital health earth concept.

\section{New disciplines and new professions}

All the technologies and capabilities required to transform this vision into reality and to build a Digital Earth are already available, such as: Computational science, Mass storage, Remote sensing imagery, Sensors, Broadband networks, Interoperability, Metadata. All this is already possible as solutions to global public health surveillance vision (Boulos, 2004). GeoAI opens up big 
opportunities and applications in health and healthcare, as location plays a key role in both population and individual health. Several disciplines within the domains of public health, precision medicine, and IoT (Internet of Things)-powered 'smart healthy cities and regions' are benefiting from GeoAI, e.g., environmental health, epidemiology, genetics and epigenetics, social and behavioral sciences, and infectious diseases, to name but a few. (Boulos, 2019)

The vision of DE should not be solely about space and spatial relations but also about place, culture and identity, spanning the entire physical and virtual space (Craglia et al. 2012). This new vision is still only slowly being adopted and there is uncertainty related to the needed competencies required in the preparation of future DE specialists. The future of DE should be planned according to education and training.

Education and training provides a liberal arts background, methodologies, and depth as well as breadth of thinking. The human is ultimately where knowledge work is done and those insights are produced in geospatial intelligence. It is dependent on the geospatial analyst's meta-knowledge.

The Training/Professional development should be built on education and expanding the knowledge base for increased performance. Training and education might happen in the digital world as part of the Digital Health Earth itself. The training and professional development should focus on the human-machine team where there is a focused effort to develop information about relationships among disparate objects and events. In terms of future professions, DE specialists for medicine, surgery, healthcare (such as nursing, social workers and community managers for public health education) and professional development can be implemented in technology, leadership, research and education itself (Alderson et al, 2020).

\section{Conclusions}

Data and reports about healthcare statistics and risk management around the world benefit from Digital Earth Project. It is important to start sketching and then design a possible layout for the implementation of a Digital Health Earth in the Digital Earth project. Although, there are several ethical implications, given aspects of human health related to privacy concerns and biological rights, spatial health related statistics (Waller \& Gotway, 2004) and community data. To be useful, data should be available in real time thanks also to emerging forms of citizen science and open publication of health data by users themselves, that would make out a Digital Health Earth accessible for everyone, with data uploading and downloading. 
Our suggestion is that the Digital Health Earth becomes a new structured area of research to produce benefits in different domains of the human health management. Digital Health Earth should include at least the following sub-domains:

1. Visualization of health data both in $2 \mathrm{D}, 3 \mathrm{D}$ and virtual/augmented reality format.

2. Geolocalization of patients.

3. Visualization of environmental data which can have an effect on human health.

4. Supply Services for public and private healthcare.

5. Monitoring of population flux and related diseases, epidemic.

6. Integration with available satellite and space technology for the purpose of human health management.

7. Global scenarios for simulation based on data driven public health and statistics about medicine, surgery and healthcare interventions.

8. 3D Healthcare literacy and dissemination of data for education, training and information to the public.

9. Design of the technology to support any of the Digital Health Earth application.

Peculiar situations, such as social exclusion or missing healthcare data would be accountable (Carr-Hill, 2013) and appear much visible substituted or integrated by data provided by samples or surveys, for instance (Carr-Hill, 2017).

Also an automated speaking version for the visual unpair should be provided in order to include as many users as possible.

WHO programs, research centers, national plans for healthcare, disaster management, public health data and other institutions should provide elements to build an interoperable representation at global level of different situations in different places at different times. This representation could be called Digital Health Earth.

\section{References}

Alderson T, Purss M, Du X, Mahdavi-Amiri A, Samavati F (2020) Digital Earth Platforms. In: Guo H., Goodchild M.F., Annoni A. (eds) Manual of Digital Earth. Springer, Singapore. https:// doi.org/10.1007/978-981-32-9915-3_2

Anderson K, Ryan B, Sonntag W et al (2017) Earth observation in service of the 2030 agenda for sustainable development. Geo-Spatial Inf Sci 20(2):77-96 
Annoni A, Craglia M, Ehlers M et al (2011) A European perspective on Digital Earth. Int J Digit Earth 4(4):271-284

Balk DL, Deichmann U, Yetman G, Pozzi F, Hay SI, and Nelson A (2006) Determining Global Population Distribution: Methods, Applications and Data. Advances in Parasitology 62: 119-156. doi: 10.1016/S0065-308X(05)62004-0

Baturin Y.M. et al. (2020) Digital Earth in Russia. In: Guo H., Goodchild M.F., Annoni A. (eds) Manual of Digital Earth. Springer, Singapore. https://doi.org/10.1007/978-981-32-9915-3_23

Boulos MNK (2004) Towards evidence-based, GIS-driven national spatial health information infrastructure and surveillance services in the United Kingdom. Int J Health Geogr 3, 1 doi: https://doi.org/10.1186

Butler D ( 2006) Virtual globes: The Web-wide world. Nature 439:776-778.

Carr-Hill R (2013) Missing Millions and Measuring Development Progress. World Development 46: 30-44. doi: 10.1016/j.worlddev.2012.12.017

Carr-Hill R (2017) Improving Population and Poverty Estimates with Citizen Surveys: Evidence from East Africa. World Development 93: 249-259. doi: 10.1016/j.worlddev.2016.12.017

Chen S (1999) The 'Digital Earth' as a global strategy and its master point. J Remote Sens 3(4):247-253

Chen S (2004) Geo-information science and Digital Earth. Science Press and Science Press USA Inc, Beijing

CIESIN (2016) Gridded Population of the World, Version 4 (GPWv4). Center for International Earth Science Information Network. Palisades, NY: Columbia University. URL: http://www.ciesin.columbia.edu/data/gpw-v4 Accessed 30 Dec 2020

CDC.gov (2012) Geography and Geospatial Science Working Group. Cartographic guidelines for public health. URL:

https://www.cdc.gov/dhdsp/maps/gisx/resources/cartographic_guidelines.pdf Accessed 30 Dec 2020

Corbane C, Pesaresi M, Politis P, Syrris V, Florczyk AJ, Soille P, Maffenini L, et al (2017) Big Earth Data Analytics on Sentinel-1 and Landsat Imagery in Support to Global Human Settlements Mapping. Big Earth Data, 1-27

Craglia M, de Bie K, Jackson D et al (2012) Digital Earth 2020: towards the vision for the next decade. Int J Digit Earth 5(1):4-21

Cromley EK, McLafferty SL (2012) GIS and Public Health. 2nd ed. New York: The Guilford 
Press.

De Longueville B, Annoni A, Schade S et al (2010) Digital Earth's nervous system for crisis events: real-time sensor web enablement of volunteered geographic information. Int J Digit Earth 3(3):242-259

Deichmann U, Balk D, and Yetman G (2001) Transforming Population Data for Interdisciplinary Usages: From Census to Grid. Palisades, NY: NASA Socioeconomic Data and Applications Center (SEDAC), CIESIN, Columbia University.

Doxsey-Whitfield E, MacManus K, Adamo SB, Pistolesi L, Squires J, Borkovska O, and Baptista SR (2015) Taking Advantage of the Improved Availability of Census Data: A First Look at the Gridded Population of the World, Version 4. Papers in Applied Geography 1 (3): 226-234. doi:10.1080/23754931.2015.1014272

Giuliani G, Wang Ch (2019) The Manual of Digital Earth: An open access publication to advance the creation of a Digital Earth. URL: https://earthobservations.org/geo_blog_obs.php? $\mathrm{id}=398$ Accessed 30 Nov 2020

FBK.eu (2020) Covid19 Infodemics Observatory. URL: https://covid19obs.fbk.eu/\#/ Accessed 30 Nov 2020

Few S (2006) Information Dashboard Design. O'Reilly. p. 223

Freire S, MacManus K, Pesaresi M, Doxsey-Whitfield E, and Mills J (2016) Development of New Open and Free Multi-temporal Global Population Grids at $250 \mathrm{~m}$ Resolution. Proceedings of the 19th AGILE Conference on Geographic Information Science, June 14-17, Helsinki.

Freire S, Schiavina M, Florczyk AJ, MacManus K, Pesaresi M, Corbane C, Borkovska O, Mills J, Pistolesi L, Squires J and Sliuzas R (2020) Enhanced data and methods for improving open and free global population grids: putting 'leaving no one behind' into practice. International Journal of Digital Earth, 13:1, 61-77, DOI: 10.1080/17538947.2018.1548656

Gaughan AE, Stevens FR, Linard C, Patel NN, and Tatem AJ (2014) Exploring Nationally and Regionally Defined Models for Large Area Population Mapping. International Journal of Digital Earth. Doi:10.1080/17538947.2014.965761

Georgiadou Y, Kounadi O, de By RA (2020) Digital Earth Ethics. In: Guo H., Goodchild M.F., Annoni A. (eds) Manual of Digital Earth. Springer, Singapore. https://doi.org/10.1007/978981-32-9915-3_25

Geospatialworld.net (2018) Adopt GIS, Be healthier. URL: https://www.geospatialworld.net/blogs/adopt-gis-be-healthier/ Accessed 30 Dec 2020 
Geraghty, E. \& Frye, C. (2020) COVID-19: The First Global Pandemic of the Information Age, Esri, 22 June https://storymaps.arcgis.com/stories/a5190c7fd6db422f9a1bab6dac024b99 Goodchild MF (1999) Implementing Digital Earth: a research agenda. In: Xu G, Chen Y (eds) Towards Digital Earth: proceedings of the International Symposium on Digital Earth. Science Press, Beijing, pp. 21-26

Goodchild MF (2000) Discrete global grids for Digital Earth. In: Proceedings of 1st international conference on discrete global grids, Citeseer, California, Santa Barbara, pp 26-28

Goodchild MF (2007) Citizens as sensors: the world of volunteered geography. GeoJournal 69(4):211-221

Goodchild MF, Guo H, Annoni A, et al (2012) Next-generation Digital Earth. Proc Natl Acad Sci U S A. 109(28):11088-11094. doi:10.1073/pnas.1202383109

Goodchild MF (2007) Citizens as sensors: The world of volunteered geography. GeoJournal. 69:211-221

Goodchild MF (2008) The use cases of digital earth. Int J Digital Earth. 1:17-30.

Gore A (1992) Earth in the balance: ecology and the human spirit. Houghton Mifflin, Boston

Guo H, Liu Z, Jiang H et al (2017) Big earth data: a new challenge and opportunity for Digital Earth's development. Int J Digit Earth 10(1):1-12

Guo H, Wang L, Chen F et al (2014) Scientific Big Data and Digital Earth. Chin Sci Bull 59(12):1047-1054

Hay SI, Noor AM, Nelson A, and Tatem AJ (2005) The Accuracy of Human Population Maps for Public Health Application. Tropical Medicine \& International Health 10 (10): 1073-1086. doi:10.1111/j.1365-3156.2005.01487.x.

He G, Wang G, Long T et al (2018b) Opening and sharing of big earth observation data: challenges and countermeasures. Bull Chin Acad Sci 33(8):783-790

Heipke C (2010) Crowdsourcing geospatial data. ISPRS J Photogramm Remote Sens 65(6):550-557

Hey AJG, Tansley S, Tolle KM (2009) The Fourth Paradigm: Data-Intensive Scientific Discovery. Redmond, WA: Microsoft Research.

ICAO (2020) Effects of Novel Coronavirus (COVID-19) on Civil Aviation. Technical report, International Civil Aviation Organisation. URL: https://www.icao.int/sustainability/Documents/Covid-19/ICAO_coronavirus_Econ_Impact.pdf Accessed 30 Dec 2020 
Ienca M, Ferretti A, Hurst S, Puhan M, Lovis C, and Vayena E (2018) Considerations for ethics review of big data health research: A scoping review. PloS one, 13(10), e0204937. DOI: https://doi.org/10.1371/journal.pone.0204937

ISDE (2012) Statutes of the International Society for Digital Earth. URL: http://www.digitalearth-isde.org/statues. Accessed 07 Oct 2020

ISDE (2014) About ISDE. URL: http://www.digitalearth-isde.org/society/54 Accessed 07 Oct 2020

Jackson D, Simpson R (2020) Digital City: An Urban Perspective on Digital Earth. In: Guo H., Goodchild M.F., Annoni A. (eds) Manual of Digital Earth. Springer, Singapore. https://doi.org/10.1007/978-981-32-9915-3_16

Jomehzadeh N, Moosavian M, Saki M, Rashno M (2019) Legionella and legionnaires' disease: An overview. J Acute Des. 8(6): 221-232 DOI: 10.4103/2221-6189.272853

Leyk S, Uhl J, Balk D, and Jones B (2018) Assessing the Accuracy of Multi-temporal Builtup Land Layers Across Rural-urban Trajectories in the United States. Remote Sensing of Environment 204: 898-917. DOI: 10.1016/j.rse.2017.08.035

Linard C, and Tatem A (2012) Large-scale Spatial Population Databases in Infectious Disease Research. International Journal of Health Geographics 11: 7. DOI: 10.1186/1476-072X-117

Liu Z, Foresman T, van Genderen J, Wang L (2020) Understanding Digital Earth. In: Guo H., Goodchild M., Annoni A. (eds) Manual of Digital Earth. Springer, Singapore

Melchiorri M, Florczyk AJ, Freire S, Schiavina M, Pesaresi M, and Kemper T (2018) Unveiling 25 Years of Planetary Urbanization with Remote Sensing: Perspectives from the Global Human Settlement Layer. Remote Sensing 10 (5): 768. DOI: 10.3390/rs10050768

Milne RJ, Kelly AR (2014) A new method for boarding passengers onto an airplane. Journal of Air Transport Management 2014, 34, 93-100. DOI:10.1016/j.jairtraman.2013.08.006

Milne RJ, Salari M (2016) Optimization of assigning passengers to seats on airplanes based on their carry-on luggage. Journal of Air Transport Management, 54, 104-110.

DOI:10.1016/j.jairtraman.2016.03.022

Pesaresi M, Ehrlich D, Florczyk AJ, Freire S, Julea A, Kemper T, Soille P, and Syrris V (2015a) GHS Built-up Grid, Derived from Landsat, Multitemporal (1975, 1990, 2000, 2014). European Commission, Joint Research Centre (JRC) [Dataset] PID. http://data.europa.eu/89h/jrcghsl-ghs_built_ldsmt_globe_r2015b 
Pesaresi M, Ehrlich D, Ferri S, Florczyk A, Freire S, Halkia S, Andreea MJ, Kemper T, Soille P, and Syrris V (2016) Operating Procedure for the Production of the Global Human Settlement Layer from Landsat Data of the Epochs 1975, 1990, 2000, and 2014. EUR - Scientific and Technical Research Reports. Publications Office of the European Union. JRC97705. URL: http://publications.jrc.ec.europa.eu/repository/handle/111111111/40182 Accessed 30 Dec 2020

Qiang SJ, Jia B, Xie DF, Gao ZY (2014) Reducing airplane boarding time by accounting for passengers' individual properties: A simulation based on cellular automaton. Journal of Air Transport Management 40, 42-47. DOI:10.1016/j.jairtraman.2014.05.007.

Rushton G, Armstrong MP, Gittler J, et al (2008) Geocoding Health Data: The Use of Geographic Codes in Cancer Prevention and Control, Research and Practice. Boca Raton, FL: CRC Press.

Schultz M, Soolaki M (2020) Analytical approach to solve the problem of aircraft passenger boarding during coronavirus pandemic 1-19

Shupeng C, and van Genderen J (2008) Digital Earth in Support of Global Change Research. International Journal of Digital Earth 1 (1): 43-65. DOI:10.1080/17538940701782510

Tangcharoensathien V, Calleja N, Nguyen T, Purnat T, D’Agostino M, Garcia-Saiso S, Landry M, Rashidian A, Hamilton C, AbdAllah A, Ghiga I, Hill A, Hougendobler D, van Andel J, Nunn M, Brooks I, Sacco PL, De Domenico M, Mai P, Gruzd A, Alaphilippe A, Briand S (2020) Framework for Managing the COVID-19 Infodemic: Methods and Results of an Online, Crowdsourced WHO Technical Consultation J Med Internet Res 22(6):e19659

Turner A (2006) Introduction to Neogeography. O'Reilly Media. p. 54

UN ECOSOC (2016) Report of the Inter-agency and Expert Group on Sustainable Development Goal Indicators. UN Economic and Social Council Statistical Commission 47th Session, E/CN.3/2016/2/Rev.1

UNDESA (2016) Sustainable Development Goals. United Nations Department of Economic and Social Affairs, Department of Economic and Social Affairs. URL:

https://sustainabledevelopment.un.org/sdgs Accessed 30 Dec 2020

UNISDR (2015) Sendai Framework for Disaster Risk Reduction 2015-2030. United Nations International Strategy for Disaster Reduction. URL:

http://www.wcdrr.org/uploads/Sendai_Framework_for_Disaster_Risk_Reduction_2015-2030.pdf Accessed 30 Dec 2020

Waller LA, Gotway CA (2004) Applied Spatial Statistics for Public Health Data. Hoboken, 
NJ: John Wiley and Sons.

WHO (2020) COVID - 19 Preparedness and response progress report. 1 February to 30 June 2020

WHO.int (1948) WHO remains firmly committed to the principles set out in the preamble to the Constitution URL: https://www.who.int/about/who-we-are/constitution Accessed 30 Nov 2020

WHO.int (2020a) WHO Coronavirus Disease (COVID-19) Dashboard. URL: https://covid19.who.int Accessed 30 Nov 2020

WHO.int (2020b) World Health Statistics. The Global Health Observatory. URL: https://www.who.int/gho/publications/world_health_statistics/2020/en/ Accessed 30 Nov 2020

WHO.int (2020c) Thirteenth General Programme of Work 2019-2023. URL: https://www.who.int/about/what-we-do/thirteenth-general-programme-of-work-2019---2023 Accessed 30 Nov 2020

Yu L, Gong P (2012) Google Earth as a virtual globe tool for Earth science applications at the global scale. International Journal of Remote Sensing 33(12):3966-3986

DOI: $10.1080 / 01431161.2011 .636081$

Zeineddine H (2017) A dynamically optimized aircraft boarding strategy. Journal of Air Transport Management 58, 144-151. DOI:10.1016/j.jairtraman.2016.10.010 